\title{
Pulse-frequency analysis of septal and hypothalamic reinforcement effects
}

\author{
J. W. KLING, D. G. BROWNLOW, S. R. MENICH, and C. A. VELOZO \\ Brown University, Providence, Rhode Island 02912
}

\begin{abstract}
Electrical stimulation of the septal or the lateral hypothalamic region was used to reinforce responding of rats. Holding constant the number, duration, and intensity of the pulses in each stimulation train, the pulse frequency was varied. Septal self-stimulation was found to be relatively invariant when every response was reinforced but was sensitive to frequency manipulations when variable interval reinforcement schedules were used. Septal self-stimulators responded most rapidly for low pulse frequencies $(50 / \mathrm{sec})$, while hypothalamic rats responded most rapidly for higher frequencies $(250-400 / \mathrm{sec})$. The frequency functions are not well accounted for by refractory period data, but do seem to represent fundamental differences in the neural substrates of reinforcement for these loci.
\end{abstract}

The very first demonstration (Olds \& Milner, 1954) of reward effects from electrical stimulation of the brain (ESB) raised the hope that an anatomical system subserving reward effects soon would be discovered. Instead, mapping experiments revealed that, although a few focal areas existed, reward effects were very widely distributed throughout the brain and did not correspond to any single anatomical entity (Olds, 1962). While it remains possible that all loci of reward effects share some neurological characteristic (e.g., a common transmitter substance), the conspicuous behavioral and physiological differences between many of the major stimulation sites (cf. Hall, Bloom, \& Olds, 1977) strongly suggest differences in neural substrates. We now report further evidence supporting the hypothesis that observed characteristics of behavior rewarded by ESB at different brain sites reflect the neurophysiological characteristics of the structures excited by the electrical stimulus.

Two sites of positive reinforcing effects whose behavioral characteristics have been studied quite thoroughly are the rat septal area and the medial forebrain bundle-lateral hypothalamic area. Typically, septal self-stimulation is slower (Hodos \& Valenstein, 1962); upon analysis, this is seen to result from a broader range of interresponse times and a characteristic intensity-dependent poststimulation pause from septal stimulation but not from hypothalamic stimulation (Terman, Terman, \& Kling, 1970). Septal self-stimulation also is punctuated by occasional

Supported in part by Grant NS-12290 to J. W. Kling and by a Biomedical Research Support Grant (PHS 5-S07-RR07085) to Brown University. D. G. Brownlow is now a consultant to the Tennessee Valley Authority; S. R. Menich is at Northeastern University; and C. A. Velozo is at Ohio University. We thank Janet Cohen for histological preparations. Reprints may be requested from J. W. Kling at Hunter Laboratory, Brown University, Providence, Rhode Island 02912. whole-body shivers and other rebound effects (Altman \& Wisehart, 1971), while hypothalamic self-stimulation is accompanied by excited, head-forward sniffing (Clarke \& Trowill, 1971; St.-Laurent, Adam-Carriere, \& Belanger, 1976; Waranch \& Terman, 1975). Hypothalamic self-stimulation rates usually show a sharp rise as current is increased, while the rate-intensity function for septal self-stimulation typically is shallow, with little evidence of a clearly demarcated "reinforcement threshold" (Olds, Travis, \& Schwing, 1960; Terman et al., 1970). When given the opportunity, animals with septal electrodes show a preference for self-control of interstimulus intervals (Meyers \& Valenstein, 1964) and select slower repetition rates for stimulus trains than do animals with hypothalamic electrodes (Valenstein \& Meyers, 1964).

Many of these behavioral differences imply neural substrates that require more time between successive trains of stimulations for septal than for hypothalamic stimulation, as if for the dissipation of some stimulation-produced inhibitory consequence (Kent \& Grossman, 1969) or for the recovery of some excitatory consequence that diminishes with septal stimulation (Olds, 1958b). If the differences are primarily secondary to the stimulation (e.g., the interfering consequences of elicited behavior), they probably would be controlled by the intervals between stimulus trains. However, if the differences are a reflection of the characteristics of the more immediate neural substrates, then these areas might be expected to show major differences in the effects of varying the frequency of the individual pulses in the stimulus trains. The behavioral characteristics suggest that peak reinforcing effects would be found at lower pulse frequency values for septal stimulation than for hypothalamic stimulation. Prior investigations of the pulse-frequency variable have found septal (Ward, 1959) and hypothalamic (Keesey, 1962; Wauquier, 
Niemegeers, \& Geivers, 1972) stimulation to increase as pulse frequency increases, reaching asymptotic response rates somewhere in the vicinity of 100 pulses/ sec but with little evidence for locus differences or preferential frequencies. In part, these results were confounded by the use of constant durations of stimulus train, so that the number of pulses per reinforcement increased as pulse frequency increased. Because number of pulses per reinforcement is itself a significant variable (Edmonds, Steller, \& Gallistel, 1974), the number of pulses was held constant across all frequencies in the present experiment.

\section{METHOD}

\section{Animals and Surgery}

Eight adult male albino rats of the Charles River CD strain were used. They were maintained with continuous access to water and one daily feeding of $20 \mathrm{~g}$ Charles River Rat Chow. Four animals were stereotactically implanted with a bipolar electrode (Plastic Products MS 303-010) aimed at the lateral septum, and four received electrodes aimed at the lateral hypothalamus. Surgery was done under inhalation anesthesia (halothane plus oxygen). Following completion of the experiment, the animals were sacrificed with an overdose of sodium pentobarbitol and perfused with physiological saline and $10 \%$ neutral buffered Formalin solution. The brains were imbedded in celloidin, sectioned at $40 \mu \mathrm{m}$, and stained with cresyl violet. Electrode loci were determined with the aid of the atlas of König and Klippel (1963) and are given in Table 1.

\section{Apparatus and Procedure}

Two weeks following surgery, each rat was placed in a test chamber $(22 \times 25 \times 55 \mathrm{~cm}$ high) and trained to press a wallmounted switch (Gerbrands pigeon key). As soon as keypressing occurred, animals were allowed to self-stimulate while the effectiveness of various intensities was explored. Each rat then received three daily 1 -h sessions during which an 8 -sec variable-interval reinforcement schedule was introduced gradually as a means of minimizing response-inhibiting reactions following massed stimulations (Beer, Hodos, \& Matthews, 1964; Terman et al., 1970). Rate-intensity functions then were determined: each rat was exposed to five levels of current, each level being presented for 6 min through six different daily series. From these functions, an intensity that supported consistent, medium rates of responding was selected for each animal.

During these 10 preliminary training days, each reinforcement consisted of a train of 24 equally spaced, rectangular, constant

Table 1

Electrode Localization

\begin{tabular}{ccccl}
\hline & & \multicolumn{2}{c}{ Locus } & \\
\cline { 3 - 4 } Rat & $\begin{array}{c}\text { Atlas } \\
\text { Plate }\end{array}$ & DV (mm) & ML (mm) & Region \\
\hline 50 & 30 & -2.8 & 1.2 & MFB-LH \\
53 & 34 & -2.4 & 1.2 & MFB-LH \\
54 & 34 & -2.4 & 1.0 & MFB-LH \\
58 & 33 & -2.2 & 1.4 & ZI \\
80 & 14 & .8 & .0 & LSN \\
82 & 10 & .6 & .8 & LSN \\
83 & 12 & .4 & .8 & LSN \\
84 & 13 & .4 & .6 & LSN \\
\hline
\end{tabular}

Note-Atlas plates are from König and Klippel (1963). MFB = medial forebrain bundle; $L H=$ lateral hypothalamus; $L S N=$ lateral septal nucleus; $Z I=$ zona incerta. current pulses. Polarity of pulses alternated. Pulses were separated by $9.9 \mathrm{msec}$, and each pulse had a duration of $.1 \mathrm{msec}$. During the next phase of the experiment, the interpulse interval was varied to produce the test frequencies; all other parameters of the stimulus train were held constant.

For each animal, a set of pulse frequencies was selected and 12 random sequences of these frequencies were constructed. Each daily test consisted of the presentation of one of these sequences, with each frequency presented for $5 \mathrm{~min}$. Timing of this interval started with the first response, which always was reinforced. Between frequency blocks, approximately $1 \mathrm{~min}$ was used to record data and change the pulse frequencies; during this period, the animal's chamber was dark and responses had no programmed consequences. During 5-min blocks, the chamber was dimly illuminated by a lamp that transilluminated the response panel. Each animal was tested for 12 consecutive days.

\section{RESULTS AND DISCUSSION}

Individual response rates were converted to proportions for purposes of graphical presentation. The results (Figure 1) show that relative self-stimulation rate is a nonmonotonic function of pulse frequency; that the most effective frequency for septal loci is relatively low (50 pulses/sec); and that the most effective frequency for lateral hypothalamic loci is much higher (250-400 pulses/sec). The mean response rate at each frequency for each animal was subjected to a one-way analysis of variance; each individual rate-frequency curve was found to have a statistically significant effect attributable to frequency $(p<.01)$. An overall ANOVA of response rates based on the eight frequencies common to all animals $(25,50$, $100,200,333,400,500$, and 1,000 pulses $/ \mathrm{sec}$ ) revealed a significant Pulse by Frequency interaction $(F=33.75$, df $=7,42 ; p<.001)$, confirming the impression given by Figure 1 that the most effective pulse frequency differs for the two loci tested.

Previous investigations of the discrete pulsefrequency parameter of electrical brain stimulation reinforcement have suggested that frequency is relatively unimportant (Gallistel, 1978) or that increasing frequencies produce increasing selfstimulation rates up to $100-140$ pulses/sec, where an asymptote is approached (Keesey, 1962; Ward, 1959; Wauquier et al., 1972). The present experiment, by holding constant the number, intensity, and duration of pulses, reveals a rather different effect and a much more influential role of pulse frequency in determining reinforcing effects.

The shapes of the self-stimulation functions show definite maxima for each locus, implying that reinforcement value at first rises and then declines with increasing pulse frequency. Such functions may indicate an optimal density of stimulation for each site. The rising limb of each function could be described adequately by a leaky-integrator model (Gallistel, 1974) or by the application of postsynaptic summation or presynaptic temporal facilitation hypotheses (Smith \& Coons, 1970). However, these approaches presumably would predict asymptotic 


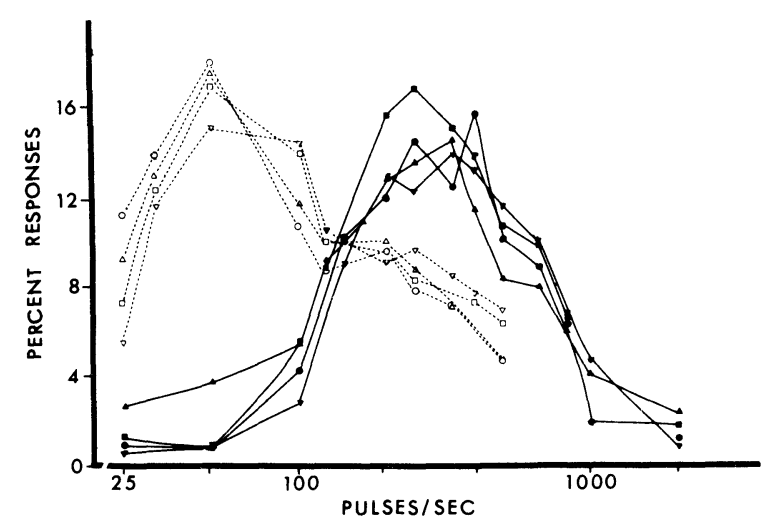

Figure 1. Relative response rate as a function of pulse frequency (log scale) of electrical brain stimulation.

reinforcing effects at higher frequencies until the limits imposed by refractory periods are reached. In the present data, the declining limb of each function appears at frequencies considerably below those that might be attributed to such transmission limitations. The systematic decline in self-stimulation rates after the optima are reached thus poses a problem for such models.

Asymmetric pulse trains have been employed in several instances as a means of estimating the refractory periods of the neural substrates of reinforcement. Basically, three methods have been used to obtain these estimates. Deutsch (1964) modified the classic Sherringtonian technique by presenting repetitive pairs of cathodal pulses which supported selfstimulation when the pulse pairs were separated by some critical interval, but which failed to sustain such responding when the interpulse interval was shortened or when the second pulse was omitted entirely. With frequent modifications, this technique has been used by many investigators (e.g., Bodnar, Steiner, Healey, Halperin, \& Ellman, 1978; Gallistel, Rolls, \& Greene, 1969; Hawkins \& Chang, 1974; Yoemans \& Davis, 1975). A second method determines relative refractory periods by noting the interpulse intervals at which the stimulating current must be increased sharply if self-stimulation is to be maintained (Smith \& Coons, 1970). These behavioral data are corroborated by physiological recordings obtained from antidromically activated units which respond twice when reinforcement sites are stimulated with paired pulses separated by certain intervals, but respond only once when shorter interpulse intervals are employed (Gallistel et al., 1969; Rolls, 1971). With all three methods, the estimated interpulse intervals necessary to support self-stimulation in hypothalamic-medial forebrain bundle sites is of the order of .6-1.2 msec. Only rarely have other regions been explored. Where telencephalic sites were included (Bodnar, Steiner, Healy, Halperin, \& Ellman, 1978), the maintenance of septal self-stimulation was found to require somewhat longer interpulse intervals (1.0-1.5 msec).

As a group, the refractory period experiments suggest that lateral hypothalamic stimulation would begin to lose effectiveness at pulse frequencies of $833 / \mathrm{sec}(1.2-\mathrm{msec}$ interpulse interval), while septal stimulation would begin to lose effectiveness at $667 \mathrm{pulses} / \mathrm{sec}$ (1.5-msec interpulse interval). In contrast, the present data show declines in selfstimulation rates beginning at much lower frequencies. It thus seems unlikely that the falling limbs of the curves can be attributed primarily to the refractory period characteristics of the neural substrates. The discrepancy between refractory period estimates and the present data are especially striking in the case of septal self-stimulation, where the peak effectiveness at 50 pulses/sec suggests a neural substrate preferentially tuned to excitation by inputs of relatively low frequencies.

In addition to assumptions involving refractory period estimates, declining limbs of reinforcement functions frequently are attributed to the increasing effects of conflicting factors. For example, the decline in self-stimulation rate as intensity of stimulation per reinforcement is increased sometimes may be ascribed to increasingly strong elicited movements ("motoric side effects") which interfere with the execution of the required response (Valenstein, 1964), or to the spread of the higher currents into regions producing punishing effects (Olds, 1958a, 1958b; Stein, 1962). Neither hypothesis seems applicable to the present data, which were obtained with stimulation of constant current and pulse number, and with variableinterval reinforcement which precluded massing of stimulation. Instead, the behavior seems reminiscent of sucrose preference functions estimated from intake (e.g., Ernits \& Corbit, 1973) or from response rates (e.g., Collier \& Siskel, 1959; Guttman, 1953), where there is little evidence for an aversive component as the cause of the descending limb.

There are some intriguing parallels between the present results and the effects of varied pulse frequencies on electrically generated taste responses. Békésy (1964) found that the threshold for eliciting a taste response (e.g., "sweet") from stimulation of an individual receptor varied in nonmonotonic form as pulse frequency increased; that receptors giving rise to the same report had the same optimal frequency; and that the probability of obtaining a given report when using electrodes of larger surface (which presumably stimulated many different receptors) varied systematically, from "sour" and "salt" at lower frequencies $(10-30 / \mathrm{sec})$ to "sweet" (70/sec) and "bitter" ( $(100 / \mathrm{sec})$. This demonstration of the frequency sensitivity in electrical activation of a sensory system does not, of course, prove that the sensory code for that system is being mimicked by 
the pulsed stimulation. It does, however, suggest that the mechanisms of the system can be sorted into frequency-specific groups. In similar fashion, the present demonstration of frequency specificity for two different loci of positive reinforcing effects demonstrates a frequency-correlated difference in their substrates. It also suggests that an analysis of pulse frequency characteristics may afford a technique for deciding which loci share common attributes. Finally, it may provide a means whereby components of the total reaction to stimulation may be evoked selectively (Hawkins \& Chang, 1974; Mogenson, Gentil, \& Stevenson, 1971; Rolls, 1973).

Because the poststimulation pause in self-stimulation places a major constraint on the rate with which the animal can respond (Terman et al., 1970), it was necessary to use some reinforcement schedule other than reinforcement of every response ("continuous reinforcement," or CRF). With a few exceptions (e.g., Kling \& Berkley, 1968), schedules other than CRF have not been applied to septal self-stimulators. It therefore was necessary to run a preliminary experiment in which the role of several schedules on the effectiveness of various pulse frequencies of septal stimulation was compared. A septal self-stimulating animal was exposed to conditions of variable-interval (VI) reinforcement, in which the first response was reinforced after an unpredictable interval had expired. The mean interval was 4,8 , or $16 \mathrm{sec}$. Pulse frequency values were presented in a different order each day, and one reinforcement schedule was in effect for any given day. The test series started with CRF, and on successive days the schedule was made increasingly sparse (VI 4-, 8-, and 16-sec schedules). The reinforcement schedule sequence then was reversed. Figure 2 shows the mean response rate at each pulse frequency when each of the reinforcement schedules was in effect. As might be

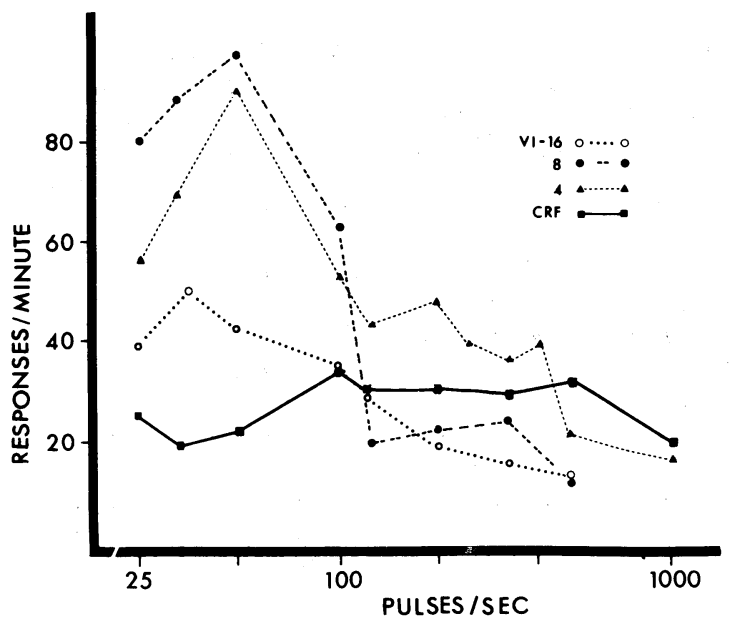

Figure 2. Responses per minute as a function of pulse frequency (log scale) of electrical brain stimulation when reinforcement is delivered after each response (CRF) or on variable interval (VI) schedules.
Table 2

Maximum Response Rates (Responses per Minute)

\begin{tabular}{cccc}
\hline Rat & Locus & Rate & $\begin{array}{c}\text { Pulses per } \\
\text { Second }\end{array}$ \\
\hline 50 & H & 126 & 400 \\
53 & H & 138 & 250 \\
54 & H & 112 & 333 \\
58 & ZI & 71 & 333 \\
80 & S & 80 & 50 \\
82 & S & 85 & 50 \\
83 & S & 90 & 50 \\
84 & S & 83 & 50
\end{tabular}

Note $-H=$ hypothalamus; $Z I=$ zona incerta $; S=$ septum.

predicted from postreinforcement pauses shown by septal self-stimulators, the response rate under CRF remained relatively constant across frequencies. As soon as the stimulation-produced constraint was weakened by allowing some responses to occur without reinforcement, a more labile response pattern emerged: at low frequencies, response rates rose above the CRF level; at high frequencies, response rates fell below this level. The VI 16-sec schedule generated occasional pauses of $60 \mathrm{sec}$ or more. Less systematic tests with other septal self-stimulators confirmed these results. It therefore was decided to test all animals under the VI 8-sec reinforcement schedule procedure.

Septal self-stimulation rates overall were lower than hypothalamic rates, which is the typical finding when these sites are compared (Hodos \& Valenstein, 1962; Kling \& Berkley, 1968; Olds, 1958a, 1958b; Olds et al., 1960; Terman et al., 1970). Mean response rates at the most effective pulse frequency are given in Table 2. It will be noted that the response rates for septal self-stimulation are considerably higher than those typically observed. These high response rates seem to attest to the efficacy of the lowfrequency stimulation condition and the utility of the variable-interval test conditions.

Two observations concerning restrictions on the generality of these data may be in order. First, the pulse-frequency effects may be peculiar to the stimulation conditions employed. Each stimulus train consisted of exactly 24 pulses, and efforts were made to insure constancy of current per pulse across the frequency range; we therefore believe that the total charge per stimulation remained constant, with only the pulse frequency (and its correlated value, pulse 1-pulse 24 time) varying. Allowing number of pulses, or current, to vary would almost certainly change the results, as each has been shown to be a significant variable in control of reinforcement effects (e.g., Edmonds et al., 1974; Keesey, 1962).

It also might be observed that the finding of optimal pulse frequencies for these loci does not necessarily imply that the neural substrates ordinarily respond to natural conditions producing reinforce- 
ment effects with such frequency patterns. The coding processes may involve variations in average frequencies of neural activity, but many other possibilities are equally plausible at this stage of our knowledge (Uttal, 1973).

\section{REFERENCES}

Altman, J. L., \& Wishart, T. B. Motivated feeding behavior elicited by electrical stimulation of the septum. Physiology \& Behavior, 1971, 6, 105-109.

Beer, B., Hodos, W., \& MAtThews, T. J. Rate of intracranial self-stimulation as a function of reinforcement magnitude and density. Psychonomic Science, 1964, 1, 321-322.

BÉ KÉSY, G. voN. Sweetness produced electrically on the tongue and its relation to taste theories. Journal of Applied Physiology, 1964, 19, 1105-1113.

Bodner, R. J., Steiner, S. S., Healey, J. M., Halperin, J., \& ELLMAN, S. J. Monophasic pulse pair analysis of intracranial self-stimulation loci. Physiological Psychology, 1978, 6, 170-178.

Clarke, S., \& Trowill, J. A. Sniffing and motivated behavior in the rat. Physiology \& Behavior, 1971, 6, 49-52.

Collier, G., \& Siskel, M., Jr. Performance as a joint function of amount of reinforcement and inter-reinforcement interval. Journal of Experimental Psychology, 1959, 57, 115-120.

DEUTSCH, J. A. Behavioral measurement of the neural refractory period and its application to intracranial self-stimulation. Journal of Comparative and Physiological Psychology, 1964, 58, 1-9.

Edmonds, D. E., Stellar, J. R., \& Gallistel, C. R. Parametric analysis of brain stimulation reward in the rat. II. Temporal summation in the reward system. Journal of Comparative and Physiological Psychology, 1974, 87, 860-869.

Ernits, T., \& Corbit, J. D. Taste as a dipsogenic stimulus. Journal of Comparative and Physiological Psychology, 1973, 83, 27-31.

Gallistel, C. R. Note on temporal summation in the reward system. Journal of Comparative and Physiological Psychology, 1974, 87, 870-875.

GALLISTEL, C. R. Self-stimulation in the rat: Quantitative characteristics of the reward pathway. Journal of Comparative and Physiological Psychology, 1978, 92, 977-998.

Gallistel, C. R., Rolls, E., \& Green, D. Neuron function inferred from behavioral and electrophysiological estimates of refractory period. Science, 1969, 166, 1028-1030.

Guttman, N. Operant conditioning, extinction, and periodic reinforcement in relation to concentration of sucrose used as a reinforcing agent. Journal of Experimental Psychology, 1953, 46, 213-224.

Hall, R. D., Bloom, F. E., \& Olds, J. (Eds.) Neuronal and neurochemical substrates of reinforcement. Neurosciences Research Program Bulletin, 1977, 15, 133-314.

Hawkins, R. D., \& Chang, J. Behavioral measurement of the neural refractory periods of stimulus-bound eating and selfstimulation in the rat. Journal of Comparative and Physiological Psychology, 1974, 86, 942-948.

Hodos, W., \& Valenste in, E. S. An evaluation of response rate as a measure of rewarding intracranial stimulation. Journal of Comparative and Physiological Psychology, 1962, 55, 80-84.

KeESEY, R. E. The relation between pulse frequency, intensity, and duration and the rate of responding for intracranial stimulation. Journal of Comparative and Physiological Psychology, 1962, 55, 671-678.

Kent, E., \& Grossman, S. P. Evidence for a conflict interpretation of anomalous effects of rewarding brain stimulation. Journal of Comparative and Physiological Psychology, 1969, 69, 381-390.

KLING, J. W., \& BerKLEY, M. A. Electrical brain stimulation and food reinforcement in discrimination and generalization situations. Journal of Comparative and Physiological Psychology, 1968, 65, 507-511.

König, J. F. R., \& KLIPPEL, R. A. The rat brain: A stereotaxic atlas of the forebrain and lower parts of the brain stem. Baltimore: Williams and Wilkins, 1963.

Meyers, W. J., \& Valenstein, E. S. Animal preference for method of obtaining reinforcing brain stimulation. Journal of Comparative and Physiological Psychology, 1964, 57, 47-51.

Mogenson, G. J., Gentil, C. G., \& Stevenson, J. A. F. Feeding and drinking elicited by low and high frequencies of hypothalamic stimulation. Brain Research, 1971, 33, 127-137.

OLDS, J. Self-stimulation of the brain. Science, 1958, 127, 315-324. (a)

OLDS, J. Satiation effects in self-stimulation of the brain. Journal of Comparative and Physiological Psychology, 1958, 51, 675-678. (b)

OLds, J. Hypothalamic substrates of reward. Physiological Review, 1962, 42, 554-603.

Olds, J., \& Milner, P. M. Positive reinforcement produced by electrical stimulation of septal area and other regions of rat brain. Journal of Comparative and Physiological Psychology, 1954, 47, 419-427.

Olds, J., Travis, R. P., \& Schwing, R. C. Topographic organization of hypothalamic self-stimulation functions. Journal of Comparative and Physiological Psychology, 1960, 53, 23-32.

Rolss, E. T. Absolute refractory period of neurons involved in MFB self-stimulation. Physiology \& Behavior, 1971, 7, 297-310.

Rolls, E. T. Refractory periods of neurons directly excited in stimulus-bound eating and drinking in the rat. Journal of Comparative and Physiological Psychology, 1973, 82, 15-22.

St.-Laurent, J., Adam-Carriere, D., \& Belanger, C. Brain stimulation and behavior in the rat: Psychiatric implications. In A. Wauquier \& E. T. Rolls (Eds.), Brain-stimulation reward. New York: American Elsevier, 1976.

Sмiтh, N. S., \& Coons, E. E. Temporal summation and refractoriness in hypothalamic reward neurons as measured by selfstimulation behavior. Science, 1970, 169, 782-785.

Ste IN, L. An analysis of stimulus-duration preference in selfstimulation of the brain. Journal of Comparative and Physiological Psychology, 1962, 55, 405-414.

Terman, J. S., Terman, M., \& KLING, J. W. Some temporal properties of intracranial self-stimulation. Physiology \& Behavior, 1970, 5, 183-191.

UTtal, W. R. The psychobiology of sensory coding. New York: Harper \& Row, 1973.

VAlenstein, E. S. Problems of measurement and interpretation with reinforcing brain stimulation. Psychological Review, 1964, 71, 415-437.

Valenstein, E. S., \& Meyers, W. J. Rate-independent test of reinforcing consequences of brain stimulation. Journal of Comparative and Physiological Psychology, 1964, 57, 52-60.

Waranch, H. R., \& Terman, M. Control of the rat's sniffing behavior by response-independent and dependent schedules of reinforcing brain stimulation. Physiology \& Behavior, 1975, 15, 365-372.

WARD, H. P. Stimulus factors in septal self-stimulation. American Journal of Physiology, 1959, 196, 779-782.

Wauquier, A., Niemegeers, C. J. E., \& Geivers, H. A. Intracranial self-stimulation in rats as a function of various stimulus parameters. I. An empirical study with monopolar electrodes in the medial forebrain bundle. Psychopharmacologia (Berl.), 1972, 23, 238-260.

Yoemans, J. S., \& Davis, J. K. Behavioral measurement of the post-stimulation excitability of neurons mediating self-stimulation by varying the voltage of paired pulses. Behavioral Biology, $1975,15,435-447$.

(Received for publication September 6, 1979; accepted September 25, 1979.) 